\title{
Flexural Fatigue-Life Assessment and Strength Prediction of Glass Fibre Reinforced Polymer Concrete Composites
}

\author{
Raman Bedi, ${ }^{1}$ S. P. Singh, ${ }^{2}$ and Rakesh Chandra ${ }^{1}$ \\ ${ }^{1}$ Department of Mechanical Engineering, Dr. B. R. Ambedkar National Institute of Technology, Jalandhar 144011, India \\ ${ }^{2}$ Department of Civil Engineering, Dr. B. R. Ambedkar National Institute of Technology, Jalandhar 144011, India \\ Correspondence should be addressed to Raman Bedi; bedir@nitj.ac.in
}

Received 18 January 2014; Accepted 4 March 2014; Published 27 March 2014

Academic Editors: M. R. Howlader, A. O. Neto, J. Provis, Y. Sun, and H. Yoshihara

Copyright (c) 2014 Raman Bedi et al. This is an open access article distributed under the Creative Commons Attribution License, which permits unrestricted use, distribution, and reproduction in any medium, provided the original work is properly cited.

\begin{abstract}
The paper presents the results of an investigation conducted to assess the fatigue-life and prediction of flexural fatigue strength of polymer concrete composites based on epoxy resin as binder material. Three point flexural fatigue tests were conducted on polymer concrete specimens using MTS servo controlled actuator, to obtain the fatigue lives of the composites at different stress levels. One hundred and thirty-seven specimens of size $40 \times 40 \times 160 \mathrm{~mm}$ were tested in flexural fatigue. Forty-three static flexural tests were also conducted to facilitate fatigue testing. It has been observed that the probabilistic distribution of fatigue-life of polymer concrete composite (PCC) and glass fibre reinforced polymer concrete composite (GFRPCC), at a particular stress level, approximately follows the two-parameter Weibull distribution, with statistical corelation coefficient values exceeding 0.90 . The fatigue strength prediction model, representing S-N relationship, has been examined and the material coefficients have been obtained for GFRPCC containing $0.5 \%$ and $1.0 \%$ glass fibres. Design fatigue lives for GFRPCC containing different contents of glass fibres have been estimated for acceptable probabilities of failure and compared with those of PCC.
\end{abstract}

\section{Introduction}

Polymer concrete composites (PCC) have been in use in the domain of civil engineering since the 1960s for various applications. Later on, due to its better properties, the material has been utilized extensively for applications such as pump base plates and machine tool bases, and so forth. Recent studies on machine tools having bases made of PCC and glass fibre reinforced polymer concrete composite (GFRPCC) have concluded that components manufactured on these have better surface finish and tolerance when compared to those with cast iron bases [1-3]. The most important reason for this is the vibration damping capability of PCC and GFRPCC which is significantly higher than conventional machine building materials like cast iron [4-6]. Fatigue loading is inevitable in these applications and, therefore, accurate characterization of fatigue behaviour of PCC and GFRPCC is of immense importance.

Studies on fatigue behaviour of PCC have been reported in literature [7-9], but a small number of specimens have been tested in most of these studies and fatigue-life distributions for PCC have not been reported. It is pertinent to note that in investigations wherein the probabilistic analysis of the fatigue data is the prime objective, it is desirable to test relatively large number of specimens at a given stress level to obtain fatigue-life data which is statistically significant.

Fatigue-life predictions based on experimental investigations report a large scatter in the fatigue-life data at same stress level, even under carefully controlled conditions. This dispersion in fatigue-life data has, therefore, been a topic of research [10-13] over the last decade. Various fatigue strength prediction models have also been proposed to predict the fatigue-life of composite materials. Most of these models provide relationship between applied stress level and number of cycles to failure $[9,11]$. To relate probability of failure with stress level and number of cycles to failure, an equation proposed by McCall [14] has been used previously for fatigue strength prediction of PCC $[7,9]$.

A number of studies on fibre reinforced polymer concrete composites (FRPCC) cite improvement in mechanical properties due to addition of fibres [15-19]. All of these studies have reported only the behaviour of PCC and FRPCC under statically applied loads. As per the information of the authors, 
no study has been reported till date on the fatigue behaviour of FRPCC. Therefore, an extensive investigation to study the flexural fatigue characteristics of PCC and FRPCC containing different contents of glass and polypropylene fibres was planned and is currently underway. The results reported here on fatigue of PCC and GFRPCC are a part of this larger investigation.

\section{Materials Used}

Epoxy resin, LAPOX-B47 along with hardener LAPOXK46 supplied by Atul Ltd., Mumbai, has been used in this investigation. The hardener and resin have been mixed in the ratio of $1: 2$ by weight. The particular grade of epoxy resin is chosen because of its low viscosity which results in better workability of the mix. Resin dosage of $10-14 \%$ by weight of PCC has been reported in literature when using coarse aggregates $[5,20,21]$ whereas higher resin dosages up to $20 \%$ have reported when using only sand as aggregate material [22]. Resin dosage of $12 \%$ by weight of PCC has been used in this investigation.

Aggregate grading plays an important role in the final properties of PCC and therefore an optimized aggregate mix suggested in literature has been used in this study [23]. Locally available crushed gravel has been used as aggregate in PCC. The aggregate mix had been optimized based upon the least void content criteria. A microfiller is also often added to PCC mix to reduce the void content in aggregate mixture and thereby increase the strength of PCC. Fly ash is a by-product of the coal burning in power plants and is used as a filler because of its easy availability and because of that its usage in PCC is reported to yield better mechanical properties as well as reduced water absorption [24]. F-type fly ash has been used in the ratio of $10 \%$ by total weight of PCC in this study.

Addition of glass fibres in PCC is reported to enhance the flexural strength, compressive strength, and so forth of the resulting material $[18,25]$. Alkali resistant macro glass fibres (Anti Crak-HP) supplied by Owens Corning India were added in PCC. The glass fibre dosage was kept at $0.5 \%$ and $1.0 \%$ by weight of PCC. The glass fibres had an average length of $12 \mathrm{~mm}$.

Aggregate material and fly ash were dried before preparation of samples to reduce moisture content below $0.5 \%$ as it has been reported that moisture content of aggregates has a deleterious effect on the properties of polymer concrete [26]. The specimens of $40 \times 40 \times 160 \mathrm{~mm}$ size were cast on a vibratory table using the materials listed above. The specimen size has been chosen as per RILEM PC-2-TC113 and has been used by a number of researchers in their work on polymer concrete $[22,27]$. The specimens were cured at room temperature for 7 days before conducting the fatigue tests as per method adopted by a number of other researchers [28-30].

\section{Estimation of Static Flexural Strength}

The estimation of static flexural strength $\left(f_{r}\right)$ of PCC and GFRPCC is a prerequisite for the selection of maximum and minimum loads to be applied during fatigue tests. The static flexural strength of the PCC and GFRPCC specimens was, therefore, evaluated prior to fatigue testing. Generally, 45 specimens from a particular batch were randomly selected and tested to determine their static flexural strength. Average static flexural strength of $24.41 \mathrm{MPa}$ was obtained for PCC, $28.16 \mathrm{MPa}$ for GFRPCC with $0.5 \%$ glass fibres, and $30.47 \mathrm{MPa}$ for GFRPCC with $1 \%$ glass fibres. It is observed that the addition of glass fibres enhances the static flexural strength of PCC. An increase of $15 \%$ in static flexural strength is observed by addition of $0.5 \%$ glass fibres by weight when compared to PCC, whereas addition of $1.0 \%$ glass fibres resulted in an increase of the static flexural strength to the tune of $25 \%$.

\section{Fatigue Testing Procedure}

All the fatigue tests were carried out on a $100 \mathrm{kN}$ MTSCyclic load testing facility in three point bending modes. The loading span was taken as $100 \mathrm{~mm}$. A stress ratio of $R=$ 0.1 was used in fatigue testing. The tests were carried out at a frequency of $10 \mathrm{~Hz}$. The minimum fatigue stress $\left(f_{\min }\right)$ and maximum fatigue stress $\left(f_{\max }\right)$ to be applied on test specimen were selected from $f_{r}$ and a particular stress level "S" $\left(f_{\max } / f_{r}\right)$. For each mix, the first test was conducted at the highest possible stress level and the number of cycles to failure was noted as fatigue-life " $N$." Subsequent tests were conducted by lowering the stress levels in a systematic manner. Since fatigue testing is a time consuming and expensive process and a large number of specimens were proposed to be tested, an upper limit of number of cycles to be applied was fixed depending upon the availability of testing equipment and time constraints. A particular test was terminated as the failure of the specimen occurred or the upper limit was reached, which ever was earlier.

\section{Analysis and Discussion of Fatigue Test Results}

The complete fatigue-life data obtained at various stress levels for PCC is reported elsewhere [31]. For GFRPCC with $0.5 \%$ and $1.0 \%$ fibres, the fatigue life data is listed in ascending order in Tables 1 and 2, respectively. Some data points listed in Tables 1 and 2 may deserve consideration for rejection as outliers. Chauvenet's criterion [32] was applied to the data points at all the stress levels tested in this investigation, and data points meeting this criterion for rejection were identified and excluded from further analysis. A few other researchers have also used the same criterion for rejection of outliers in their work on fatigue $[12,13]$.

\section{Fatigue-Life Distributions of PCC and GFRPCC}

Weibull distribution function has proved to be useful and versatile means of describing fatigue behaviour of cement concrete [12, 33] as well as other composite materials [13]. This is because the probability density function of the Weibull distribution has a wide variety of shapes. Therefore, because 
TABLE 1: Laboratory fatigue-life data for GFRPCC-0.5\% (number of cycles to failure).

\begin{tabular}{lccc}
\hline$S=0.85$ & $S=0.8$ & $S=0.75$ & $S=0.7$ \\
\hline 1744 & 8937 & 87451 & $548^{*}$ \\
2024 & 15425 & 98154 & 124128 \\
2155 & 17458 & 99451 & 145125 \\
3215 & 18373 & 110254 & 225135 \\
3745 & 19124 & 145125 & 286541 \\
4129 & 23366 & 164373 & 345125 \\
4417 & 28541 & 198451 & 467215 \\
4815 & 34397 & 284152 & 484316 \\
5964 & 38541 & 345125 & 614512 \\
6863 & 45215 & 385145 & 894851 \\
$129951^{*}$ & - & - & 905421 \\
\hline
\end{tabular}

${ }^{*}$ Rejected as outlier by Chauvenet's criteria, not included in analysis.

TABLE 2: Laboratory fatigue-life data for GFRPCC-1.0\% (number of cycles to failure).

\begin{tabular}{lccc}
\hline$S=0.85$ & $S=0.8$ & $S=0.75$ & $S=0.7$ \\
\hline 9851 & 46554 & 80506 & $2147^{*}$ \\
14611 & 51974 & 164251 & 160750 \\
17739 & 68451 & 185475 & 254158 \\
19845 & 84533 & 248514 & 358415 \\
24975 & 96541 & 384824 & 502418 \\
26415 & 102145 & 442152 & 694280 \\
28451 & 124154 & 463496 & 1214514 \\
31820 & 135412 & 621398 & 1335054 \\
44125 & 243771 & 712214 & 1442515 \\
51974 & 275863 & 910863 & 1524152 \\
- & - & - & 1858145 \\
- & - & - & $2000000^{* *}$ \\
\hline
\end{tabular}

* Rejected as outlier by Chauvenet's criteria, not included in analysis.

${ }^{* *}$ Run-out, not included in analysis.

of physically valid assumptions, sound experimental verification, relative ease in its use, and better developed statistics, the Weibull distribution is being used extensively for statistical description of fatigue-life data.

\section{Analysis of Fatigue-Life Data by Graphical Method}

A two-parameter Weibull distribution function is characterized by a cumulative distribution function (CDF), $F(n)$ as follows:

$$
F(n)=1-\exp \left[-\left(\frac{n}{u}\right)^{\alpha}\right]
$$

in which $n=$ specific value of the random variable $N$; $\alpha=$ shape parameter or Weibull slope at stress level $S$ and $u=$ scale parameter or characteristic life at stress level $S$.

The probability of survival or survivorship function or reliability function, $L_{R}(n)$, may be defined as $L_{R}(n)=1-F(n)$, and substituting this value of $F(n)$ in (2) and taking logarithm on both sides, it is modified to

$$
\ln \left[\ln \frac{1}{L_{R}}\right]=\alpha \ln (n)-\alpha \ln (u) .
$$

Equation (2) represents a linear relationship between $\ln \left[\ln \left(1 / L_{R}\right)\right]$ and $\ln (n)$. In order to obtain a graph from (2), the fatigue-life data corresponding to a particular stress level are first arranged in ascending order of cycles to failure and the empirical survivorship function $L_{R}$ for each of fatigue-life data at a given stress level is obtained from the following relation [32]:

$$
L_{R}=1-\frac{i}{k+1}
$$

where $i$ denotes the failure order number and $k$ represents the number of data points in a data sample under consideration at a particular stress level $S$. The empirical survivorship function in the form of $\ln \left[\ln \left(1 / L_{R}\right)\right]$ for each of fatigue-life data is then plotted on a graph with the corresponding fatigue lives $\ln (N)$. If a linear trend is established for the data points, the best fit line is drawn using method of least squares. It can then be assumed that fatigue-life data for that particular stress level follows the two-parameter Weibull distribution. The slope of the line provides an estimate of shape parameter $\alpha$ and the characteristic life $u$ can be obtained as that value of $n$ which corresponds to $L_{R}=0.368$. It has been reported elsewhere by the authors [31] that fatigue-life data for PCC approximately follows a two-parameter Weibull distribution. Figure 1 presents the fatigue-life data for few selected stress levels plotted as described above for GFRPCC- $-5 \%$ and GFRPCC-1\%. The approximate straight line plots in this figure with statistical correlation coefficients " $r$ " exceeding 0.9 indicated that the two-parameter Weibull distribution is a reasonable assumption for the statistical distribution of fatigue-life for GFRPCC. Similar results have been obtained at all the stress levels in this investigation. The estimated parameters thus obtained are listed in Table 3.

\section{Analysis of the Fatigue-Life Data by the Method of Maximum Likelihood Estimate}

The method of maximum likelihood estimate can also be used to obtain the Weibull parameters. The probability density function of the Weibull distribution can be rewritten as follows [34]:

$$
f_{N}(n)=\frac{\alpha}{\theta} n^{\alpha-1} \exp \left[-\frac{n^{\alpha}}{\theta}\right]
$$

where

$$
\theta=u^{\alpha}
$$

The likelihood function may then be expressed as

$$
L_{N}\left(\alpha, \theta \mid n_{1}, n_{2}, \ldots, n_{k}\right)=\prod_{i=1}^{k} f\left(n_{i} \mid \alpha, \theta\right) .
$$


TABLE 3: Parameters of Weibull distribution for GFRPCC.

\begin{tabular}{|c|c|c|c|c|c|c|}
\hline \multicolumn{7}{|c|}{ Glass fibre reinforced polymer concrete composite (GFRPCC-0.5\%) } \\
\hline \multirow{2}{*}{ Stress level " $S$ " } & \multicolumn{2}{|c|}{ Graphical method } & \multicolumn{2}{|c|}{ Method of maximum likelihood } & \multicolumn{2}{|c|}{ Average } \\
\hline & $\alpha$ & $u$ & $\alpha$ & $u$ & $\alpha$ & $u$ \\
\hline 0.85 & 2.10 & 4505 & 2.65 & 4412 & 2.37 & 4458 \\
\hline 0.8 & 2.01 & 28817 & 2.48 & 28214 & 2.24 & 28515 \\
\hline 0.75 & 1.71 & 222787 & 2.00 & 218052 & 1.85 & 220419 \\
\hline 0.7 & 1.42 & 520972 & 1.76 & 506980 & 1.59 & 513976 \\
\hline
\end{tabular}

Glass fibre reinforced polymer concrete composite (GFRPCC-1.0\%)

\begin{tabular}{|c|c|c|c|c|c|c|}
\hline \multirow{2}{*}{ Stress level "S" } & \multicolumn{2}{|c|}{ Graphical method } & \multicolumn{2}{|c|}{ Method of maximum likelihood } & \multicolumn{2}{|c|}{ Average } \\
\hline & $\alpha$ & $u$ & $\alpha$ & $u$ & $\alpha$ & $u$ \\
\hline 0.85 & 1.98 & 31088 & 2.34 & 30564 & 2.16 & 30826 \\
\hline 0.8 & 1.62 & 141795 & 1.80 & 139436 & 1.71 & 140615 \\
\hline 0.75 & 1.31 & 492291 & 1.72 & 473692 & 1.51 & 482991 \\
\hline 0.7 & 1.15 & 1095935 & 1.60 & 1041980 & 1.37 & 1068957 \\
\hline
\end{tabular}

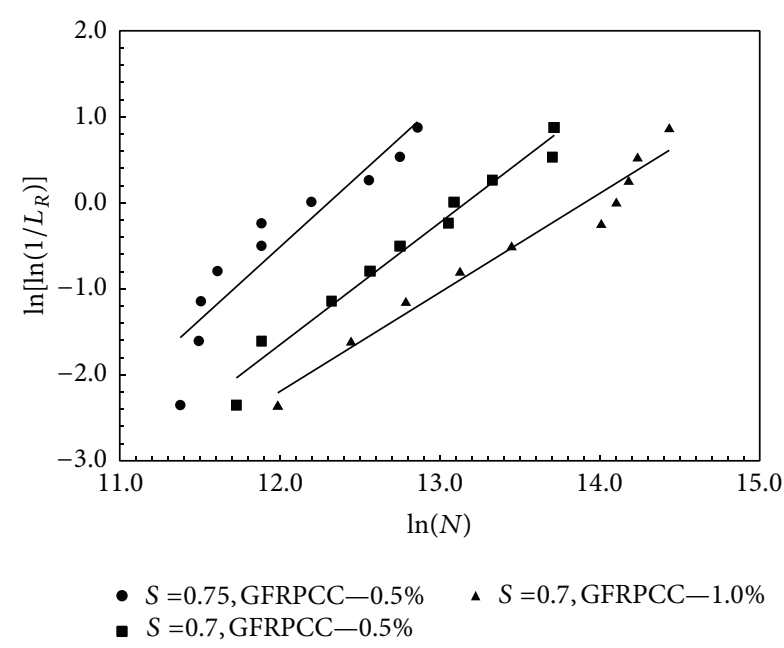

FIgURE 1: Graphical analysis of fatigue-life data for GFRPCC.

Equation (6) leads to the log likelihood function; that is,

$$
\begin{aligned}
\ln \left(L_{N}\left(\alpha, \theta \mid n_{1}, n_{2}, \ldots, n_{k}\right)\right) & =\ln \left[\prod_{i=1}^{k} f\left(n_{i} \mid \alpha, \theta\right)\right] \\
& =\sum_{i=1}^{k} \ln \left[f\left(n_{i} \mid \alpha, \theta\right)\right] .
\end{aligned}
$$

Taking partial derivatives for the log likelihood function with respect to $\alpha$ and $\theta$ and setting the equations equal to zero and solving for $\alpha$ and $\theta$, the following equations are obtained [34]:

$$
\begin{gathered}
\theta^{*}=\frac{1}{k} \sum_{i=1}^{k} n_{i}^{\alpha^{*}}, \\
\frac{\sum_{i=1}^{k} n_{i}^{\alpha^{*}} \ln \left(n_{i}\right)}{\sum_{i=1}^{k} n_{i}^{\alpha^{*}}}-\frac{1}{\alpha^{*}}=\frac{1}{k} \sum_{i=1}^{k} \ln \left(n_{i}\right),
\end{gathered}
$$

where $\alpha^{*}$ and $\theta^{*}$ are the maximum likelihood estimators of $\alpha$ and $\theta$, respectively, and $i$ is the failure order number and $k$ represents the number of data points in a data sample.

Thus (5), (8), and (9) can be used to estimate the Weibull parameters for the fatigue-life data at various stress levels for GFRPCC having different fibre contents. Firstly, the shape parameter $\alpha$ is obtained by (9) by a trial and error procedure. As a first trial, the average value of shape parameter $\alpha$ calculated by the graphical method and the method of moments can be used. Then the maximum likelihood estimator $\theta$ for the fatigue-life data, at a particular stress level, is calculated from (8). Finally, the parameter $\mathrm{u}$ is determined from (5). The Weibull parameters as obtained in this investigation for GFRPCC with $0.5 \%$ glass fibers and GFRPCC with $1.0 \%$ glass fibers are also listed in Table 3.

It can be seen from the results that there is significant decrease in the values of shape parameters for GFRPCC compared to PCC whose results are reported elsewhere by the authors [31]. This indicates higher variability in the distribution of fatigue-life data of GFRPCC compared to PCC. A maximum decrease of approximately $17 \%$ at $S=0.75$ has been observed with the addition $0.5 \%$ glass fibres to PCC. Similarly, a maximum decrease of the order of $34 \%$ at $S=0.80$ has been observed with the addition of $1.0 \%$ of glass fibres to PCC.

\section{Fatigue Strength Prediction Model}

A form of fatigue equation commonly used by the researchers for prediction of fatigue strength of materials is given by (10) as follows [35]:

$$
S=C_{1}(N)^{-C_{2}} .
$$

A distinct feature of this equation is that the value of $N$ as $S$ becomes small. This equation satisfies the extreme boundary condition by having $N$ approach infinity as $S$ approaches zero. To obtain the material coefficients $C_{1}$ and $C_{2}$, take log of (10) on both sides,

$$
\log (S)=\log \left(C_{1}\right)-C_{2} \log (N) .
$$




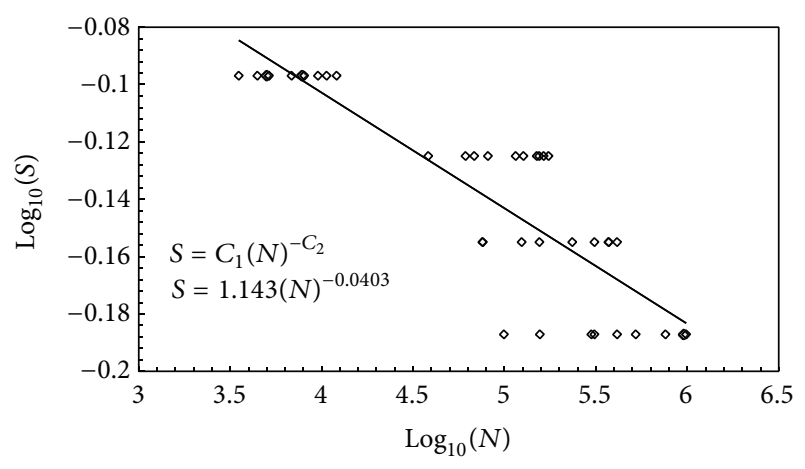

Figure 2: Estimation of coefficients $C_{1}$ and $C_{2}$ of (10) for PCC.

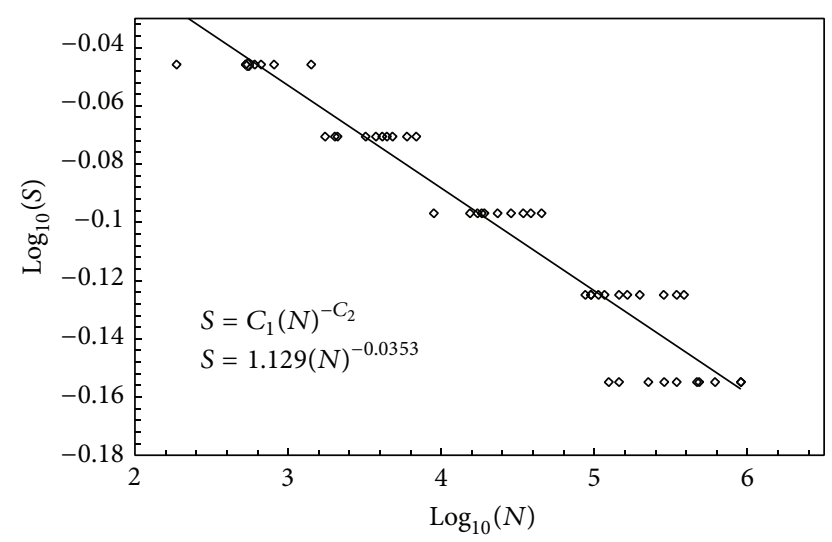

FIgURE 3: Estimation of coefficients $C_{1}$ and $C_{2}$ of (10) for GFRPCC- $0.5 \%$.

TABle 4: Coefficients $C_{1}$ and $C_{2}$ for (10).

\begin{tabular}{lcc}
\hline Material & Coefficient $C_{1}$ & Coefficient $C_{2}$ \\
\hline PCC & 1.143 & 0.0403 \\
GFRPCC-0.5\% & 1.129 & 0.0353 \\
GFRPCC-1.0\% & 1.186 & 0.0360 \\
\hline
\end{tabular}

A plot is drawn between $\log (S)$ and $\log (N)$, where $N$ is the fatigue-life data obtained for GFRPCC at different stress levels $S$ tested in present investigation. The material coefficients $C_{1}$ and $C_{2}$ are thus obtained from the regression analysis.

Figures 2, 3, and 4 present the analysis to estimate coefficients $C_{1}$ and $C_{2}$ for PCC and GFRPCC containing $0.5 \%$ and $1.0 \%$ fibres, respectively, and the estimated values of $C_{1}$ and $C_{2}$ are listed in Table 4 . The fatigue-life data reported for PCC elsewhere [31] has been used in Figure 2.

\section{Estimation of Design Fatigue Lives}

The fatigue-life data obtained in this investigation for GFRPCC witness large scatter. This is usually expected in the fatigue-life data even at a given stress level under carefully controlled test procedures. For PCC reinforced with fibres, that is, GFRPCC, this variability in the distribution of fatiguelife substantially increases compared to that of plain PCC.

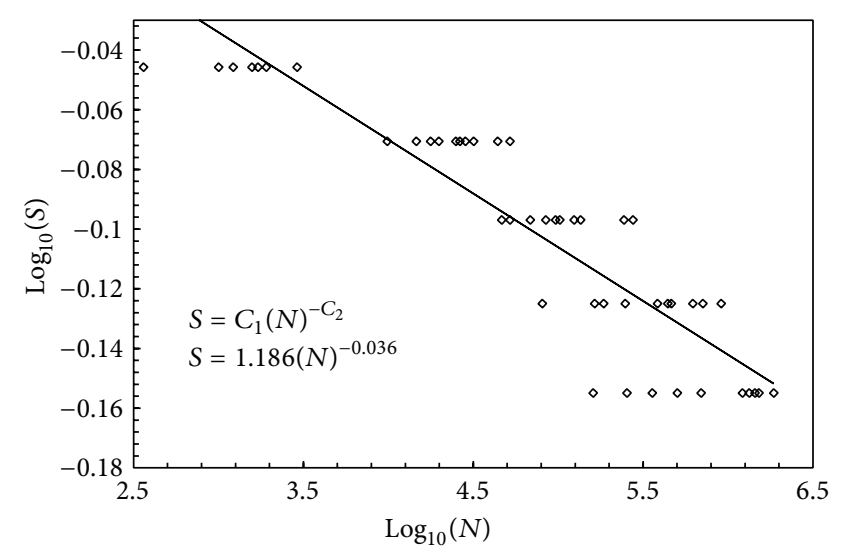

Figure 4: Estimation of coefficients $C_{1}$ and $C_{2}$ of (10) for GFRPCC-1.0\%.

The design fatigue-life $N_{D}$ should be selected such that there is only a small probability that a fatigue failure will occur. Once the distribution function is determined as above, the design fatigue-life $N_{D}$ may be selected corresponding to an acceptable probability of failure. The design reliability may be expressed as $L_{N}\left[N>N_{D}\right]=1-P_{f}$, in which $P_{f}$ is the probability of failure. Thus the design fatigue-life $N_{D}$ corresponding to a permissible probability of failure $P_{f}$ can be obtained from (2) as follows [12]:

$$
N_{D}=u\left[\ln \frac{1}{1-P_{f}}\right]^{1 / \alpha} .
$$

Using the average values of the Weibull parameters $\alpha$ and $\mathrm{u}$ corresponding to different stress levels for the fatigue-life data of GFRPCC as in Table 3, (12) has been used to calculate the design fatigue lives corresponding to selected acceptable probabilities of failure $\left(P_{f}\right)$, that is, $0.01,0.05,0.10,0.15$, and 0.25 . The calculated design fatigue lives corresponding to selected probabilities of failure are listed in Tables 5 and 6 for GFRPCC containing $0.5 \%$ and $1.0 \%$ glass fibres, respectively. The "design fatigue-life curves" have been generated, using the design fatigue lives for GFRPCC listed in above tables, which could be useful to the design engineers. Figures 5 and 6 present the design fatigue-life curves for GFRPCC containing $0.5 \%$ glass fibers and GFRPCC containing $1.0 \%$ glass fibers, respectively.

It can be observed that addition of fibres into PCC enhances the fatigue-life of the resulting material. This increase is proportional to the amount of fibre addition within the range used in present investigation. Figure 7 presents the comparison between the design fatigue lives at a constant probability of failure, $P_{f}=0.15$ for fatigue-life data of PCC reported by the authors elsewhere [31] with that of GFRPCC with varying fibre content. It can be observed that, for a particular stress level $S$, the GFRPCC with $1.0 \%$ glass fibre content has the highest design fatigue-life, followed by GFRPCC with $0.5 \%$ fibre content and PCC. This indicates that the best fatigue performance is given by GFRPCC with $1.0 \%$ fibre content, followed by GFRPCC with $0.5 \%$ and PCC if the performance is examined in terms of applied 
TABLE 5: Design fatigue lives " $N_{D}$ " at different probabilities of failure $P_{f}$, for GFRPCC $-0.5 \%$.

\begin{tabular}{lcccrc}
\hline & & $P_{f}$ & & \\
& 0.01 & 0.05 & 0.10 & 0.15 & \\
Stress level, $S$ & & & Design fatigue lives, $N_{D}$ & \\
0.85 & 639 & 1273 & 1724 & 2071 & 12864 \\
0.80 & 3734 & 7705 & 10610 & 81778 & 16581 \\
0.75 & 18018 & 43696 & 64616 & 163929 \\
0.70 & 28474 & 79370 & 124817 & 234766 \\
\hline
\end{tabular}

TABLE 6: Design fatigue lives " $N_{D}$ " at different probabilities of failure $P_{f}$, for GFRPCC-1.0\%.

\begin{tabular}{|c|c|c|c|c|c|}
\hline & \multicolumn{5}{|c|}{$P_{f}$} \\
\hline & 0.01 & 0.05 & 0.10 & 0.15 & 0.25 \\
\hline Stress level, $S$ & \multicolumn{5}{|c|}{ Design fatigue lives, $N_{D}$} \\
\hline 0.85 & 3664 & 7793 & 10875 & 13292 & 17314 \\
\hline 0.80 & 9543 & 24756 & 37713 & 48592 & 67858 \\
\hline 0.75 & 22955 & 67558 & 108819 & 144997 & 211643 \\
\hline 0.70 & 37213 & 122292 & 206817 & 283777 & 430533 \\
\hline
\end{tabular}

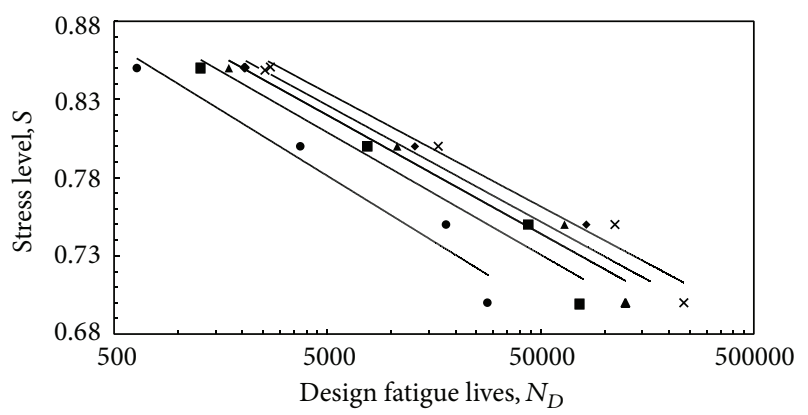

$$
\begin{array}{ll}
\text { - } P_{f}=0.01 & \text {. } P_{f}=0.15 \\
\text { - } P_{f}=0.05 & \times P_{f}=0.25 \\
\text { - } P_{f}=0.1 &
\end{array}
$$

FiguRE 5: Design fatigue-life curves for GFRPCC-0.5\%.

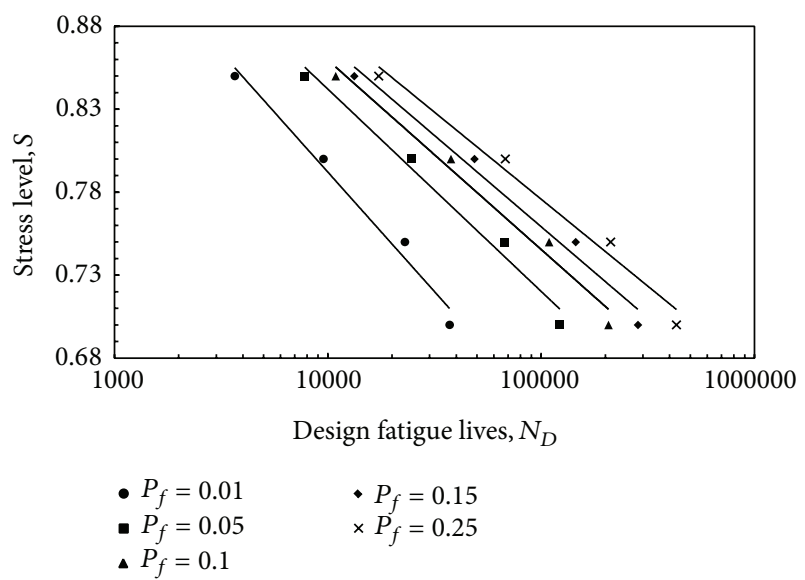

FIGURE 6: Design fatigue-life curves for GFRPCC-1.0\%.

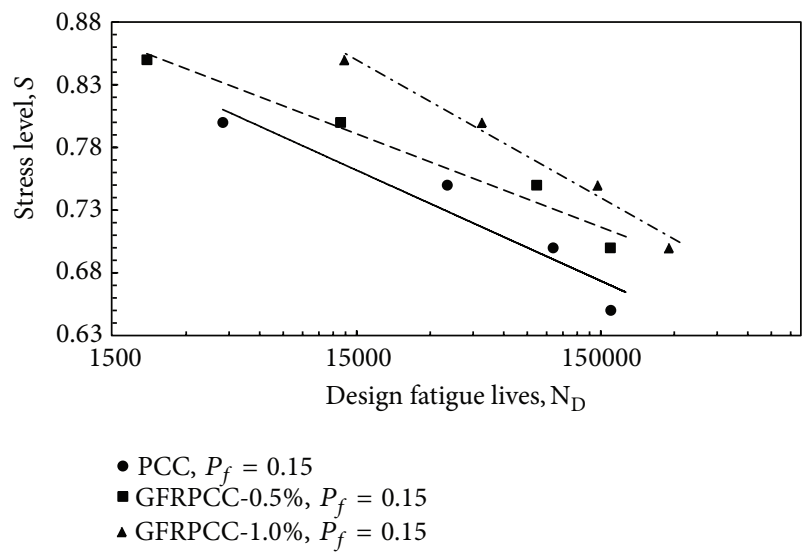

FIGURE 7: Comparison of design fatigue-life curves for PCC and GFRPCC.

fatigue stress expressed as a percentage of corresponding static flexural stress, that is, stress level $S$.

\section{Conclusions}

Flexural fatigue tests were conducted to obtain the fatigue lives of PCC and GFRPCC at different stress levels. Test data obtained has been analysed to establish the probability distributions of GFRPCC using two-parameter Weibull distribution and compared with PCC. Design fatigue lives have also been determined for PCC and GFRPCC and design fatiguelife curves have been generated. It has been seen that addition of glass fibres to PCC results in larger variability in the distribution of flexural fatigue lives of resulting material, that is, 
GFRPCC. On the other hand, significant improvements in the design fatigue lives have been observed for GFRPCC compared with PCC. Further, the fatigue strength prediction model representing $S-N$ relationship has been examined and the material coefficients of the model have been estimated for PCC and GFRPCC containing different contents of fibres. The model can be used to predict the flexural fatigue strength of PCC and GFRPCC.

\section{Conflict of Interests}

The authors declare that there is no conflict of interests regarding the publication of this paper.

\section{References}

[1] C. Bruni, A. Forcellese, F. Gabrielli, and M. Simoncini, "Hard turning of an alloy steel on a machine tool with a polymer concrete bed," Journal of Materials Processing Technology, vol. 202, no. 1-3, pp. 493-499, 2008.

[2] C. Bruni, A. Forcellese, F. Gabrielli, and M. Simoncini, "Effect of the lubrication-cooling technique, insert technology and machine bed material on the workpart surface finish and tool wear in finish turning of AISI 420B," International Journal of Machine Tools and Manufacture, vol. 46, no. 12-13, pp. 15471554, 2006.

[3] M. Rahman, M. A. Mansur, L. K. Lee, and J. K. Lum, "Development of a polymer impregnated concrete damping carriage for linear guideways for machine tools," International Journal of Machine Tools and Manufacture, vol. 41, no. 3, pp. 431-441, 2001.

[4] S. Orak, "Investigation of vibration damping on polymer concrete with polyester resin," Cement and Concrete Research, vol. 30, no. 2, pp. 171-174, 2000.

[5] F. Cortés and G. Castillo, "Comparison between the dynamical properties of polymer concrete and grey cast iron for machine tool applications," Materials \& Design, vol. 28, no. 5, pp. 14611466, 2007.

[6] R. Bedi and A. Singh, "Adaptive neuro-fuzzy inference system in modelling damping performance of epoxy polymer concrete," International Journal of Materials Engineering Innovation, vol. 4, pp. 18-34, 2013.

[7] C. J. Chang, G. A. Woelfl, and M. McNerney, "Flexural fatigue of polymer concrete," Cement, Concrete and Aggregates, vol. 3, no. 2, Article ID CCA10209J, 1981.

[8] K. Kobayashi, Y. Ohama, and T. Ito, "Fatigue properties of resin concrete under repeated compression loads," Seisan Kenkyu, vol. 26, pp. 116-118, 1974.

[9] C. Vipulanandan and S. Mebarkia, "Fatigue crack growth in polyester polymer concrete," American Concrete Institute, vol. 201, pp. 153-168, 2001.

[10] S. P. Singh, Y. Mohammadi, and S. K. Madan, "Flexural fatigue strength of steel fibrous concrete containing mixed steel fibres," Journal of Zhejiang University SCIENCE A, vol. 7, no. 8, pp. 1329$1335,2006$.

[11] S. P. Singh and S. K. Kaushik, "Flexural fatigue analysis of steel fiber-reinforced concrete," ACI Materials Journal, vol. 98, pp. 306-312, 2001.

[12] S. P. Singh and S. K. Kaushik, "Flexural fatigue life distributions and failure probability of steel fibrous concrete," ACI Materials Journal, vol. 97, pp. 658-667, 2001.
[13] R. Bedi and R. Chandra, "Fatigue-life distributions and failure probability for glass-fiber reinforced polymeric composites," Composites Science and Technology, vol. 69, no. 9, pp. 1381-1387, 2009.

[14] J. T. McCall, "Probability of fatigue failure of plain concrete," Journal of the American Concrete Institute, vol. 55, pp. 233-244, 1958.

[15] S. Mebarkia and C. Vipulanandan, "Compressive behavior of glass-fiber-reinforced polymer concrete," Journal of Materials in Civil Engineering, vol. 4, no. 1, pp. 91-105, 1992.

[16] C. Vipulanandan and S. K. Mantrala, "Behavior of fiber reinforced polymer concrete," in Proceedings of the 4th Materials Engineering Conference, pp. 1160-1169, November 1996.

[17] K. Sett and C. Vipulanandan, "Properties of polyester polymer concrete with glass and carbon fibers," ACI Materials Journal, vol. 101, pp. 30-41, 2004.

[18] J. Reis, "Mechanical characterization of fiber reinforced polymer concrete," Materials Research, vol. 8, pp. 357-360, 2005.

[19] J. Reis and A. Ferreira, "Fracture behavior of glass fiber reinforced polymer concrete," Polymer Testing, vol. 22, no. 2, pp. 149-153, 2003.

[20] A. Fattah and M. El-Hawary, "Flexural behavior of polymer concrete," Construction and Building Materials, vol. 13, no. 5, pp. 253-262, 1999.

[21] K. Rebeiz, S. Serhal, and A. P. Craft, "Properties of polymer concrete using fly ash," Journal of Materials in Civil Engineering, vol. 16, no. 1, pp. 15-19, 2004.

[22] A. J. M. Ferreira, C. Tavares, and C. Ribeiro, "Flexural properties of polyester resin concretes," Journal of Polymer Engineering, vol. 20, no. 6, pp. 459-468, 2000.

[23] M. Muthukumar, D. Mohan, and M. Rajendran, “Optimization of mix proportions of mineral aggregates using Box Behnken design of experiments," Cement and Concrete Composites, vol. 25, no. 7, pp. 751-758, 2003.

[24] K. T. Varughese and B. K. Chaturvedi, "Fly ash as fine aggregate in polyester based polymer concrete," Cement and Concrete Composites, vol. 18, no. 2, pp. 105-108, 1996.

[25] T. W. Brockenbrough, "Fiber reinforced methacrylate polymer concrete," ACI Journal, pp. 322-325, 1982.

[26] Y. Ohama, "Mix proportions and properties of polyester resin concretes," American Concrete Institute, pp. 283-294, 1973.

[27] M. Ribeiro, C. M. L. Tavares, M. Figueiredo, A. J. M. Ferreira, and A. A. Fernandes, "Bending characteristics of resin concretes," Materials Research, vol. 6, no. 2, pp. 247-254, 2003.

[28] K. S. Rebeiz, "Time-temperature properties of polymer concrete using recycled PET," Cement and Concrete Composites, vol. 17, pp. 119-124, 1995.

[29] M. E. Tawfik and S. B. Eskander, "Polymer concrete from marble wastes and recycled poly(ethylene terephthalate)," Journal of Elastomers and Plastics, vol. 38, no. 1, pp. 65-79, 2006.

[30] Y. Ohama and K. Demura, "Relation between curing conditions and compressive strength of polyester resin concrete," International Journal of Cement Composites and Lightweight Concrete, vol. 4, pp. 241-244, 1982.

[31] R. Bedi, R. Chandra, and S. P. Singh, "Probabilistic analysis of fatigue life of polymer concrete," Journal of Experimental \& Applied Mechanics, vol. 4, no. 3, pp. 22-28, 2013.

[32] J. B. Kennedy and A. M. Neville, Basic Statistical Methods for Engineers and Scientists, A Dun-Donnelley Publishers, 1986. 
[33] S. Goel, S. P. Singh, and P. Singh, "Fatigue analysis of plain and fiber-reinforced self-consolidating concrete," ACI Materials Journal, vol. 109, pp. 573-582, 2012.

[34] Y. Mohammadi and S. K. Kaushik, "Flexural fatigue-life distributions of plain and fibrous concrete at various stress levels," Journal of Materials in Civil Engineering, vol. 17, no. 6, pp. 650658, 2005.

[35] S. Goel, S. P. Singh, and P. Singh, "Flexural fatigue strength and failure probability of self compacting fibre reinforced concrete beams," Engineering Structures, vol. 40, pp. 131-140, 2012. 

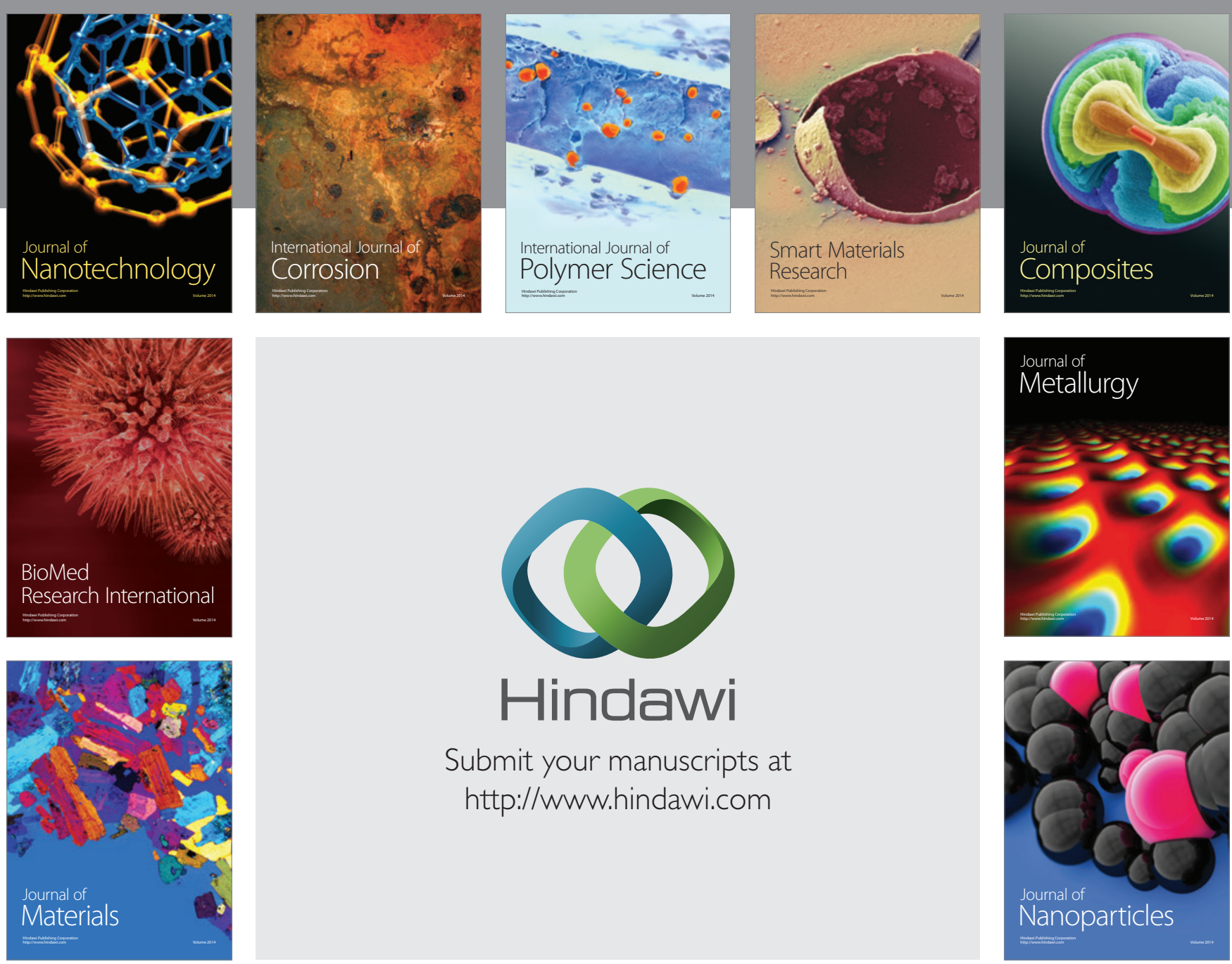

Submit your manuscripts at http://www.hindawi.com
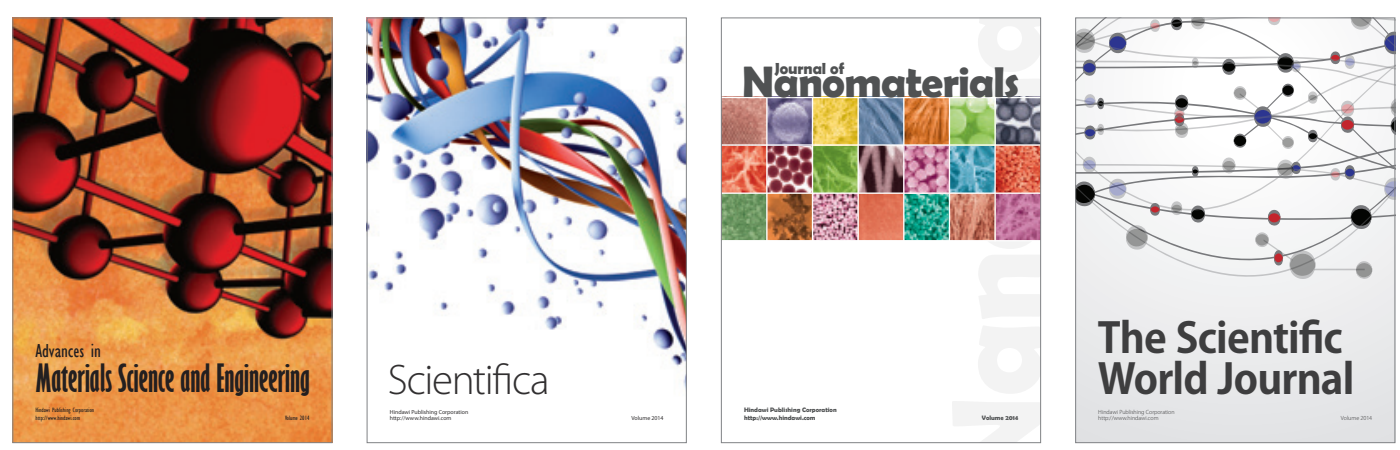

\section{The Scientific World Journal}
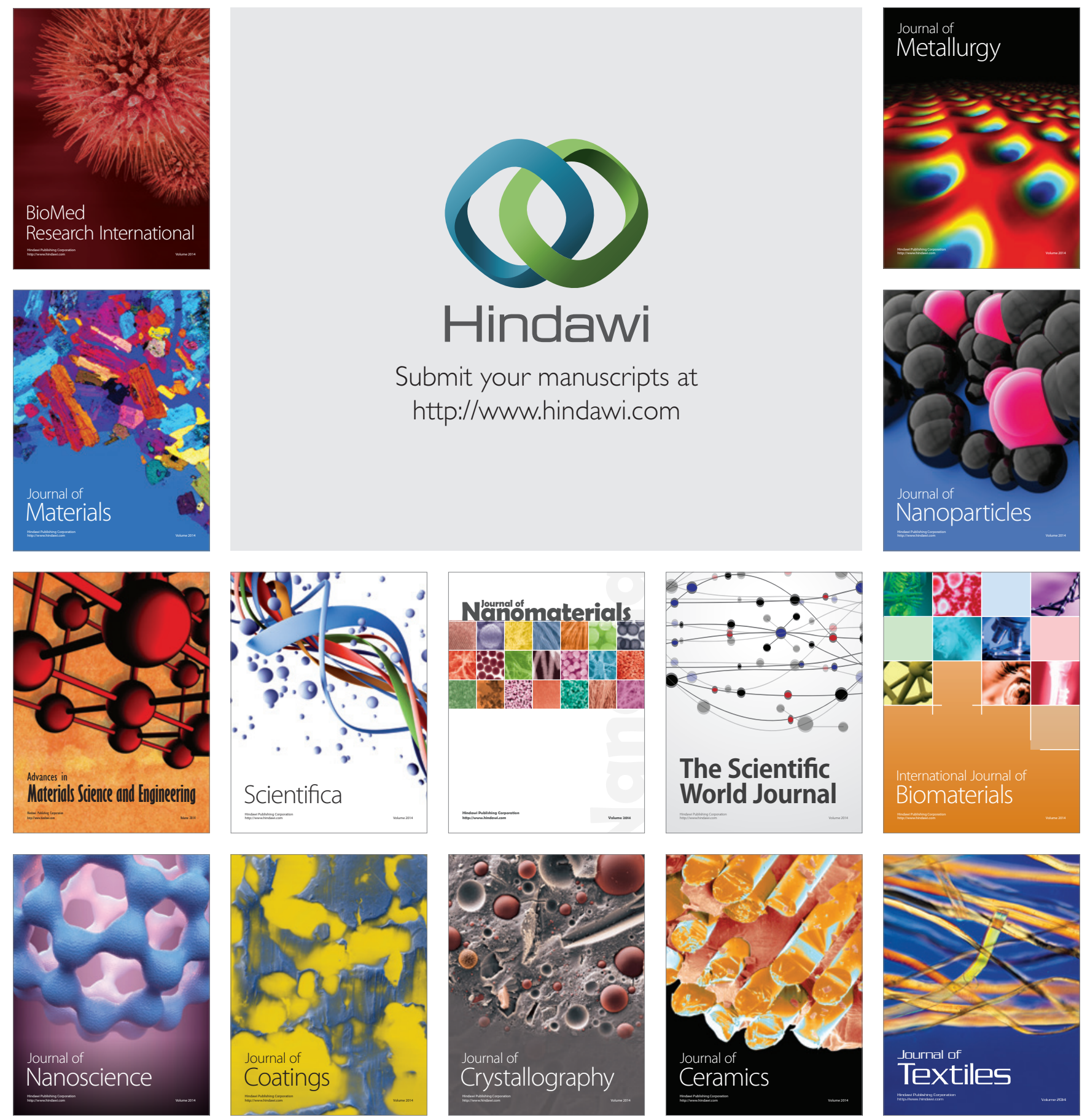